\title{
Evaluation of Stress Hormone (Cortisol) Levels and Some Biochemical Parameters of Pigs Kept Under Intensive Management Systems in Morogoro, Tanzania
}

\author{
Gaymary George Bakari (Corresponding Author)
}

Department of Veterinary Physiology, Biochemistry and Pharmacology, P.O. Box 3017, College of Veterinary and Biomedical Sciences, Sokoine University of Agriculture, Morogoro, E mail: manemgay@yahoo.com; gaymary.bakari@sua.ac.tz

\section{Ester Mollel}

Department of Veterinary Medicine and Public Health, P. O. Box 3021, College of Veterinary and Biomedical Sciences, Sokoine University of Agriculture, Morogoro, Tanzania.

\section{Robert Arsen Max}

Department of Veterinary Physiology, Biochemistry and Pharmacology, P.O. Box 3017, College of Veterinary and Biomedical Sciences, Sokoine University of Agriculture, Morogoro, Tanzania. Email: robertmax@sua.ac.tz

Amandus P. Muhairwa

Department of Veterinary Medicine, P. O. Box 3021, College of Veterinary and Biomedical Sciences, Sokoine University of Agriculture, Morogoro, Tanzania

Email: apm@sua.ac.tz

Received: May 6, 2018 Accepted: May 21, 2018

doi:10.5296/jbls.v9i2.13424 URL: https://doi.org/10.5296/jbls.v9i2.13424 


\section{Abstract}

The worldwide increase in demand for animal products in recent decades has necessitated raising of food animals under intensive systems that have been demonstrated to cause stress to animals. A cross sectional study was carried conducted to evaluate the welfare of pigs kept under intensive system using serum cortisol levels and some biochemical parameters as indicators of stress. A total of 302 pigs, aged three months to two years, from urban and peri-urban areas of Morogoro township were purposively involved in the study which assessed farm management aspects (housing and feeding) and blood levels of cortisol and some biochemical parameters (glucose, total protein and cholesterol). Results showed that serum cortisol levels were significantly higher $(\mathrm{p}<0.001)$ in pigs from the peri-urban farms than those dwelling in the urban settings. Weaner pigs and boars had the highest serum cortisol levels compared to growers, gilts and sows. Significantly high levels of plasma cholesterol $(\mathrm{p}<0.05)$ were measured in boars followed by gilts and weaners all kept in the urban areas whereas insignificant differences were observed as far as plasma glucose and total proteins were concerned. Result on farm management assessment showed that urban piggery housing was of better quality than in the peri-urban and that feeding was largely influenced by local availability of the major feed ingredients such as maize bran and vegetable residues. About $80 \%$ of urban pigs were maintained on high concentrate feed due to availability of swills (restaurant leftovers) and maize bran whereas low concentrate feed with mainly vegetable residues dominated in the peri-urban settings. It is concluded that, serum cortisol levels observed in the current study were a reflection of stress to different groups of pigs kept under the intensive system and that feeds had some direct effect on biochemical parameters such as plasma cholesterol levels.

Keywords: Stress factors, biochemical parameters, cortisol, pigs, urban, peri-urban

\section{Introduction}

Pig farming is an important component of the livestock sector in Tanzania. Pig keeping is practiced by small scale farmers due to its relatively low cost of establishment and its potential role as a contributor to increased rural household incomes and to improved food security in households (Wilson and Swai, 2014). In recent years there has been a growing concern about animal welfare due to the undesirable consequences on general productivity performance (Miró et al 2016). Increased demand for quality animal products has led to intensification of production that compromises with animal welfare (Barnet et al 2001; Cadiani et al., 2008). Intensive management has been reported to restrict movements and freedom to access feeds causing stress in pigs (Verdon et al 2015). Social interactions and aggressive behaviour has been shown to increases as the space allowance decreased in group-housed sows (Weng et al., 1998; Verdon et al., 2015). Other factors include environmental stress such as temperature, humidity, light, concentration of dust and gases, ammonia levels and sound intensity. Metabolic stress results from food and/or water restriction or deprivation (Pearce et al., 2013; Sanz et al., 2015). Subjecting pigs to a stressful environment has been found to increase blood cortisol levels and also interfere with biochemical parameters such as blood glucose, cholesterol and total protein (Maduka et al., 
2015).

Cortisol, a steroid hormone in the glucocorticoid class of hormones, is normally released into the blood stream in response to stress and low blood-glucose concentration in most mammals (Aronson, 2005; Maduka et al., 2015). In most diurnal species, cortisol is secreted with a circadian variation that is, high concentrations at late night and early morning and with low concentrations in the afternoon and early night (Sjaastad et al., 2003). Blood glucose, cholesterol and total protein are biochemical parameters which have also received considerable attention as indicators in assessing animal welfare (Doyle et al., 2015). Recently, animal welfare report has highlighted the need for improving animal welfare for good production. There is paucity of information on studies to assess the influence of management aspects on serum cortisol levels and some blood parameters in pigs in the country. The purpose of this study was therefore to evaluate the welfare of pigs kept under intensive system using serum cortisol levels and some biochemical profiles as indicators of stress.

\section{Materials and Methods}

\subsection{Study area and animal descriptions}

The study was conducted from April to June in urban (Morogoro town, 500 - $600 \mathrm{~m}$ asl, 25 $30^{\circ} \mathrm{C}$ ) and peri-urban areas (Mgeta, $1500-1700 \mathrm{~m}$ asl, $16-20^{\circ} \mathrm{C}$ ) in Morogoro region, Tanzania. These areas were chosen because they were known to have substantial number of small scale pig farms having least 10 animals and above per household. A total of 302 pigs of both sexes ranging from 3 months to two years of age were involved in the study. 140 pigs were from peri urban whereas 162 were from urban Morogoro. Distribution of sampled areas, stage and sex of pigs is shown in Table 1.

Table 1. Number of pigs by sex and growth stage

\begin{tabular}{lccccc}
\hline Growth stage & Total number & Urban & Peri urban & Female & Male \\
\hline Boars & 14 & 7 & 7 & NA & 14 \\
Sows & 92 & 69 & 23 & 92 & NA \\
Gilts & 34 & 5 & 29 & 34 & NA \\
Growers & 70 & 23 & 47 & 23 & 47 \\
Weaners & 92 & 34 & 58 & 44 & 48 \\
Total & 302 & 138 & 164 & 193 & 109 \\
\hline
\end{tabular}

\subsection{Study design and assessment of farm management}

A cross-sectional study was employed; it involved purposive sampling of units with at least 10 animals and above. At the farm level, all pigs above three months of age were involved in the study. A well-designed checklist was used to assess farm management aspects (housing and feeding). Pig house were classified as $1=$ ideal (with concrete floor, division of pens and roof with corrugated iron sheets; $2=$ moderate (i.e. concreate floor, divisions of pens and 
thatch roof; 3 = poor (i.e., sandy floor, no divisions of pens and roof with thatch/no roof). Feeding was categorised into three levels based on energy value: $1=$ high concentrate diet (> $80 \%$ depends on food remains from restaurants i.e., swills and $20 \%$ maize bran), $2=$ moderate concentrate (50\% mixture of food remains and $50 \%$ maize bran) and $3=$ low concentrate diet (70\% depend on horticultural crop residues and 30\% maize bran).

\subsection{Blood sample collection and handling}

Blood samples were collected early in the morning between 8 and 10 am to avoid a circadian variation of cortisol and heat stress. Animals were restrained using pig snare; to minimize stress to animals only two operators were allowed in a pen at a time. Blood samples (about 5 $\mathrm{mL}$ ) were collected directly from the anterior vena cava using plain and heparinized vacutainer for cortisol and biochemical analyses respectively. Samples were transported to a laboratory at the CVMS using cool boxes. In the laboratory, the samples were centrifuged at $3,000 \mathrm{rpm}$ to obtain serum and plasma, which were refrigerated at $4^{0} \mathrm{C}$ pending analysis.

\subsection{Determination of cortisol and biochemical parameters}

Serum cortisol levels were determined using micro plate enzyme immunoassay (Accu Bind ELISA Microwell). This is a competitive immunoassay specifically designed and validated for the quantitative measurement of cortisol in serum. Biochemical parameters (plasma glucose and cholesterol) were analysed using standard methods as explained by Trinders (1969) Erba ${ }^{\circledR}$ kits. This involves the reaction between hydrogen peroxide, phenol and aminoantipyrine which is catalyzed a peroxidase to form a quinone. The resulting quinone is red-violet in colour being its intensity is proportion to the glucose concentration which measured at $540 \mathrm{~nm}$. Total protein was determined by Biuret method using Erba ${ }^{\circledR}$ test kit as described by WHO (2006) whereby cupric ions $\left(\mathrm{Cu}^{2+}\right)$ in the biuret reagent complexes with the groups involved in the peptide bond. In the presence of alkaline media i.e. $3 \% \mathrm{NaOH}$ and at least two peptide bonds a violet colored chelate is formed and pink reddish violet due to the complexity of the peptide bond in the protein measured at $546 \mathrm{~nm}$.

\subsection{Data analysis}

The results were analyzed using SPSS statistical package version 20 (2011). Data were subjected to univariate analyses using two-way ANOVA and t-test to compare mean values among different variables. Tests were conducted at $95 \%$ confidence interval and significance level of $5 \%$ was considered significant.

\section{Results}

In the current study, pigs from the peri-urban farms had significantly higher serum cortisol levels $(4.96 \pm 0.19 \mu \mathrm{g} / \mathrm{dL} ; \mathrm{p}<0.001)$ than their urban counterparts $(3.11 \pm 0.15 \mu \mathrm{g} / \mathrm{dL})$. Moreover, weaner pigs and boars had significantly higher levels $(\mathrm{p}<0.001)$ compared to the other tested groups. The diet offered had significant influence $(\mathrm{p}<0.05)$ on serum cortisol level in that pigs fed on low concentrate diet had significantly higher serum cortisol levels than those maintained on moderate or high concentrate diets (Table 2).

Plasma cholesterol levels were significantly higher $(\mathrm{p}<0.05)$ in male pigs than in their 
female counterparts particularly in boars from the urban farms (Table 3). It was further observed that pigs maintained on level 1 feed (> 80\% depends on food remains from restaurants i.e., swills and $<20 \%$ maize bran) had high cholesterol concentration than those on low concentrate diet. Plasma concentrations of glucose were not significantly different ( $p>0.05$ ) among different groups although boars had higher levels in comparison to other groups in both study areas. Also, pigs maintained on moderate concentrate diet had higher plasma glucose levels than those receiving high concentrate diets. Plasma total protein did not differ significantly $(\mathrm{p}>0.05)$ among pig groups of location and the levels were within normal range i.e.6.1 - $6.9 \mathrm{mg} / \mathrm{dL}$.

Table 2. Serum cortisol levels in different groups of pigs

\begin{tabular}{lllll}
\hline & & \multicolumn{3}{c}{ Cortisol $(\mu \mathrm{g} / \mathrm{dL})^{*}$} \\
\cline { 3 - 5 } Sex & Female & $3.67 \pm 0.17$ & $3.08 \pm 0.18$ & $4.85 \pm 0.29$ \\
\cline { 3 - 5 } & Male & $3.81 \pm 0.24$ & $3.39 \pm 0.37$ & $4.21 \pm 0.25$ \\
Location & NA & NA & $3.11 \pm 0.15$ & $4.94 \pm 0.22$ \\
Stage & Boar & $4.96 \pm 0.19^{* * *}$ & $4.11 \pm 0.13$ & $5.66 \pm 1.79^{* * *}$ \\
& Gilt & $3.12 \pm 0.20$ & $2.87 \pm 0.59$ & $4.39 \pm 0.39$ \\
& Grower & $3.21 \pm 0.88$ & $4.31 \pm 0.28$ & $5.19 \pm 0.56^{* * *}$ \\
& Sow & $3.39 \pm 0.72$ & $3.13 \pm 0.28$ & $4.98 \pm 0.56^{* *}$ \\
& Weaner & $3.77 \pm 0.28$ & $4.57 \pm 0.18$ & $5.71 \pm 0.52^{* * *}$ \\
Diet & High & NA & $3.01 \pm 0.27$ & NA \\
& Moderate & NA & $3.23 \pm 0.28$ & NA \\
& Low & NA & NA & $4.96 \pm 0.19$ \\
\hline
\end{tabular}

Degree of significance: $*(p<0.05) ; * *(p<0.01) ; * * *(p<0.001)$. Normal values of serum cortisol in pigs: $2.75-3.18 \mu \mathrm{g} / \mathrm{dL}$ [Radostitis et al 2000] 
Table 3 Plasma biochemical parameters of pigs from selected urban and peri-urban areas of Morogoro

\begin{tabular}{|c|c|c|c|c|c|c|c|c|c|c|}
\hline & & \multicolumn{3}{|c|}{ Glucose (mg/dL) } & \multicolumn{3}{|c|}{ Total protein $(\mathrm{g} / \mathrm{dL})$} & \multicolumn{3}{|c|}{ Cholesterol (mg/dL) } \\
\hline & & Overall & Urban & Peri urban & Overall & Urban & Peri urban & Overall & Urban & Peri urban \\
\hline \multirow[t]{2}{*}{ Sex } & Female & $80.2 \pm 1.9$ & $82.1 \pm 3.1$ & $78.4 \pm 2.3$ & $6.5 \pm 0.9$ & $6.4 \pm 0.1$ & $6.5 \pm 0.1$ & $78.4 \pm 2.8$ & $98.9 \pm 4.3$ & $57.9 \pm 2.4$ \\
\hline & Male & $86.5 \pm 2.5$ & $87.7 \pm 4.1$ & $85.3 \pm 3.2$ & $6.2 \pm 0.1$ & $6.2 \pm 0.1$ & $6.2 \pm 02$ & $84.2 \pm 3.8$ & $107.4 \pm 8.0$ & $61.0 \pm 2.6$ \\
\hline \multirow[t]{5}{*}{ Stage } & Boar & $90.7 \pm 2.2$ & $104.1 \pm 10.1$ & $94.6 \pm 10.3$ & $6.3 \pm 0.1$ & $5.8 \pm 0.2$ & $7.0 \pm 0.6$ & $59.5 \pm 3.4$ & $131.9 \pm 31.8^{* *}$ & $44.6 \pm 5.4$ \\
\hline & Gilt & $83.0 \pm 2.2$ & $81.2 \pm 4.6$ & $77.8 \pm 10.0$ & $6.3 \pm 0.1$ & $6.4 \pm 0.5$ & $6.2 \pm 0.2$ & $103.2 \pm 3.3$ & $110.8 \pm 40.2$ & $66.3 \pm 3.8$ \\
\hline & Grower & $98.0 \pm 9.0$ & $88.4 \pm 4.6$ & $80.2 \pm 3.7$ & $6.2 \pm 0.5$ & $6.4 \pm 0.5$ & $6.2 \pm 0.2$ & $81.9 \pm 10.8$ & $110.9 \pm 40.2^{* *}$ & $66.3 \pm 3.8$ \\
\hline & Sow & $76.8 \pm 7.3$ & $88.8 \pm 5.5$ & $82.0 \pm 3.1$ & $6.3 \pm 0.4$ & $6.6 \pm 1.6$ & $6.9 \pm 0.3$ & $106.3 \pm 8.8$ & $95.7 \pm 5.5$ & $52.4 \pm 4.2$ \\
\hline & Weaner & $84.1 \pm 2.8$ & $78.7 \pm 3.6$ & $78.9 \pm 4.9$ & $6.4 \pm 0.1$ & $6.1 \pm 0.2$ & $6.2 \pm 0.1$ & $86.9 \pm 3.4$ & $102.1 \pm 8.6$ & $59.6 \pm 3.0$ \\
\hline \multirow[t]{3}{*}{ Diet } & High & $84.2 \pm 2.5$ & $68.4 \pm 2.6^{*}$ & NA & $6.7 \pm 0.1$ & $6.2 \pm 0.2$ & NA & $79.1 \pm 3.0$ & $150.5 \pm 5.1$ & NA \\
\hline & Moderate & $77.8 \pm 2.9$ & $96.5 \pm 2.8^{*}$ & NA & $6.1 \pm 0.1$ & $6.4 \pm 0.3$ & NA & $89.6 \pm 3.5$ & $56.7 \pm 3.1$ & NA \\
\hline & Low & $68.4 \pm 2.6$ & NA & $83.5 \pm 2.0$ & $6.1 \pm 0.2$ & NA & $6.5 \pm 0.1$ & NA & NA & $59.2 \pm 6.9$ \\
\hline
\end{tabular}

Degree of significance: $*(p<0.05)$; $* *(p<0.01)$. Normal values: [Plasma glucose $85-150 \mathrm{mg} / \mathrm{dL}$; Total protein 3.5-6 g/dL; Total cholesterol $28-48 \mathrm{mg} / \mathrm{dL}$ adapted from Radostits et al 2000]

Result on farm management assessment showed that intensive system, whereby pigs are housed in a flock of 5 to over 40 animals and partitioned into different pens depending on the growth stage and physiological status was the most commonly practiced pig farming system in the study area. About 53\% of piggery housing were categorized as class 1 and 2 and were all found in the urban area whereas the remaining percent was class 3 and were all in the peri-urban settings. The nature/type of feeds used in the two study areas was largely influenced by local availability of the major feed ingredients such as maize bran and vegetable residues. About $80 \%$ of urban pigs were maintained on high concentrate feed due to availability of swills (restaurant leftovers) and maize bran whereas low concentrate feed with mainly vegetable residues dominated in the peri-urban settings. 


\section{Discussion}

The current study evaluated the welfare of pigs kept under intensive system using serum cortisol levels and some biochemical profiles as indicators of stress. The high levels of serum cortisol in peri urban pigs could be a result of some stress factors which were observed to associate management, i.e., housing and feeding. For instance, poor housing without proper roofing and partitioning was a characteristic feature of peri-urban farms involved in this study; which may have subjected the animals to environmental and social stress. Feeding of low concentrate diet to peri-urban might have also contributed to higher serum cortisol as a compensatory mechanism to low energy intake. As a regulator of metabolizable energy in the body, serum cortisol increases hepatic gluconeogenesis and the peripheral release of substrates, primarily from muscle, required for gluconeogenesis (Velazco et al., 2013; Maduka et al., 2015).

Findings on plasma biochemical parameters revealed a remarkable association with the type of feed offered to the animals. That is, the high levels of plasma cholesterol in urban pigs were due to the fact that the animals were maintained on high concentrate feed with large proportion of swills known to contain large quantities of fats and carbohydrate. A similar trend was observed in case of the plasma glucose although the difference was not statistically significant. Undoubtedly, the nature of feeds used in the study area was mainly affected by availability and affordability of feed components such as maize, wheat, sorghum, soybean and sunflower which increases competition for basal feed with human and poultry for feed resources, thus increasing cost of production. Also, recurrence of droughts due to global warming are exacerbating the situation thus resulted into increased cost of production in the pig industry (Kanengoni 2016).

The current study also revealed that intensive system, whereby pigs are permanently housed in a flock of 5 to over 40 animals, is the most practised system in Morogoro. Similar findings were reported by Wilson and Swai (2014) who observed that in rural areas of Tanzania, pigs are totally confined in rudimentary housing of local materials and with little consideration for hygiene or general welfare. In this study, it was further noted that majority (80\%) of pigs kept were breeding sows, growers, weaners and fewer males. This showed that most farmers get rid of male pigs through selling, culling or exchanging them with males from a distant pig keeper to avoid inbreeding; this is an interesting observation implying that most small-scale farmers had knowledge on good piggery management. This observation differs from findings by Karimuribo et al (2011) who noted that the majority of small-scale farms in Iringa Region had more growers, followed by adult pigs and relatively small proportion of piglets.

It is concluded that, serum cortisol levels and the biochemical profiles observed in the current study were a reflection of stress to different groups of pigs kept under the intensive system. 


\section{MlMacrothink}

\section{Acknowledgements}

The authors appreciate the Ministry of Foreign Affairs of Denmark through Danish International Development agency (DANIDA) for financial support (12- P02-TAN). The funder had no role in the study design, data collection and analysis, decision to publish, or preparation of the manuscript.

\section{Competing interests}

The authors declare that they have no competing interests.

\section{References}

Aronson, D. (2005). Cortisol - Its Role in Stress, Inflammation, and Indications for Diet Therapy Today's Dietitian 11(11) 38. Retrieved from

www.todaysdietitian.com/newarchives/111609p38.shtml

Barnett, J. L., Hemsworth P. H., Cronin, G. M., Jongman, E. and Hutson, G. D. (2001). A review of the welfare issues for sows and piglets in relation to housing. Australian Journal of Agriculture and Research, 52(1)1-28.

Candiani, D, G. Salamano, E. Mellia, L. Doglione, R. Bruno, Toussaint M. and Gruys, E. (2008). A Combination of Behavioral and Physiological Indicators for Assessing Pig Welfare on the Farm. Journal of Applied Animal Welfare Science, 11(1)1-13. DOI: $10.1080 / 10888700701729080$.

Doyle R. E., Lee, C., McGill, D. M. and Mendl, M. (2015). Evaluating pharmacological models of high and low anxiety in sheep Peer-reviewed Journal, (12), [e1510]. DOI: 10.7717/peerj.1510.

Kanengoni, A. (2016). Feeding pigs in Africa is expensive. Changing their diets is the answer. The Conversation; Academic rigour, journalistic flair.

$\mathrm{http}$ ///theconversation.com/feeding-pigs-in-africa-is-expensive-changing-their-diets-is-the-ans wer-65171 November 20, 2016.

Karimuribo E. D., Chenyambuga, S. W., Makene V. W. and Mathias S. (2011). Characteristics and production constraints of rural-based small-scale pig farming in Iringa region, Tanzania. Livestock Research for Rural Development, 23(8)1-9.

Maduka I C., Neboh, I. E. and Ufelle, S. A. (2015). The relationship between serum cortisol, adrenaline, blood glucose and lipid profile of undergraduate students under examination stress. African Health Science, 15(1) 131-136.

Miró, S. M., Fernando, T., Ramón, M., Escribano, D., Fuensanta, H., Madrid, J., Orengo, J., Martínez, S., Manteca, X. and José, J. C. (2016). Causes, consequences and biomarkers of stress in swine: an update BMC Veterinary Research, 12:171 DOI 10.1186/s12917-016-0791-8.

Pearce ,S. C., Gabler, N. K., Ross, J. W., Escobar, J., Patience, J. F, Rhoads, R P,, Baumgard, L. H. (2013). The effects of heat stress and plane of nutrition on metabolism in growing pigs. 
Journal of Animal Science, 91(5)2108-18.

Radostits, O. M., Gay, C. C., Blood, D. C. and Hinchcliffe, K. W. (2000). Appendix 3 Laboratory Reference Values: Biochemistry Clinical Examination of Farm Animals. Ed. Peter G.G. Jackson, Peter D. Cockcroft Copyright (C) 2002 by Blackwell Science Ltd. Veterinary Medicine, 9th edn, W.B. Saunders, London, pp. 1819-1822.

Sanz, M V., Johnson, J. S., Abuajamieh, M., Stoakes, S. K., Seibert, J. T., Cox, L., Kahl, S., Elsasser, T H., Ross, J. V., Isom, S. C. (2015). Effects of heat stress on carbohydrate and lipid metabolism in growing pigs. Physiological Reports, 3(2): e12315.

Sjaastad, Ø.V., Sand, O., and Hove K. (2003). Physiology of Domestic Animals. Scandinavian Veterinary Press, Physiology ISBN 8291743118, 9788291743110.

Trinder, P. (1969). Determination of glucose in blood using glucose oxidase with an alternative oxygen acceptor. Annals of Clinical Biochemistry; 6: 24-25.

Velazco, O. R. B., Sanz, S. C., Fernando, E. B. and García, A. V. (2013). Comparison of extensive and intensive pig production systems in Uruguay in terms of ethologic, physiologic and meat quality parameters. Revista Brasileira de Zootecnia, 42(7)521-529. ISSN 1806-9290. http://dx.doi.org/10.1590/S1516-35982013000700009.

Verdon, M, C. F., Hansen, J. L., Rault, E., Jongman, L., Hansen, U., Plush, K., Hemsworth, P. H. (2015). Effects of group housing on sow welfare: a review. Journal of Animal Science 93(5)1999-2017.

Weng, R. C., Edwards, S. A., English, P. R. (1998). Behaviour, social interactions and lesion scores of group-housed sows in relation to floor space allowance. Applied Animal Behavioural Science ,59:307-16.

Wilson R, T, and Swai, E. S. (2014). Pig Production in Tanzania: A Critical Review. Tropicultura, 32(1)46-53.

\section{Copyright Disclaimer}

Copyright for this article is retained by the author(s), with first publication rights granted to the journal.

This is an open-access article distributed under the terms and conditions of the Creative Commons Attribution license (http://creativecommons.org/licenses/by/3.0/). 